\title{
Hippocampal mitogen-activated protein kinase activation is associated with intermittent hypoxia in a rat model of obstructive sleep apnea syndrome
}

\author{
YA-NING ZHAO ${ }^{1}$, HONG-YANG WANG ${ }^{2}$, JIAN-MIN LI ${ }^{2}$, BAO-YUAN CHEN ${ }^{2}$, \\ GUO XIA ${ }^{2}$, PAN-PAN ZHANG ${ }^{1}$ and YAN-LEI GE ${ }^{2}$ \\ Departments of ${ }^{1}$ Rehabilitation and ${ }^{2}$ Respiratory Medicine, Affiliated Hospital of Hebei United University, \\ Tangshan, Hebei 063000, P.R. China
}

Received November 5, 2014; Accepted August 5, 2015

DOI: $10.3892 / \mathrm{mmr} .2015 .4505$

\begin{abstract}
Obstructive sleep apnea syndrome (OSAS), characterized by intermittent hypoxia/re-oxygenation, may impair the cerebral system. Although mitogen-activated protein kinase (MAPK) signaling was observed to have a key role in hypoxia-induced brain injury, the intracellular events and their underlying mechanisms for intermittent hypoxia/re-oxygenation-associated damage to hippocamal MAPKs, including extracellular signal-regulated kinase (ERK)1/2, P38MAPK and c-Jun N-terminal kinase (JNK) remain to be elucidated and require further investigation. A total of five rats in each sub-group were exposed to intermittent hypoxia or continued hypoxia for 2, 4, 6 or 8 weeks. Histological, immunohistochemical and biological analyses were performed to assess nerve cell injury in the hippocampus. Surviving CA1 pyramidal cells were identified by hematoxylin and eosin staining. The levels of phosphorylated ERK1/2, P38MAPK and JNK were detected by western blotting. B-cell lymphoma 2 (Bcl-2) and $\mathrm{Bcl}-2$-associated $\mathrm{X}$ protein $(\mathrm{Bax})$ in neural cells were examined by immunohistochemistry. The malondialdehyde (MDA) contents and superoxide dismutase (SOD) activities were measured by thiobarbituric acid and xanthine oxidation methods, respectively. Under continued hypoxia, the levels of phospho-ERK1/2 peaked at the fourth week and then declined, whereas phospho-P38MAPK and JNK were detected only in the late stages. By contrast, under intermittent hypoxia, ERK1/2, P38MAPK and JNK were activated at all time-points assessed (2, 4, 6 and 8 weeks). The levels of phospho-ERK1/2,
\end{abstract}

Correspondence to: Dr Hong-Yang Wang, Department of Respiratory Medicine, Affiliated Hospital of Hebei United University, 78 Jian She South Road, Tangshan, Hebei 063000, P.R. China E-mail: wanghyw8@163.com

Key words: B-cell lymphoma-2-associated X protein, obstructive sleep apnea syndrome, mitogen-activated protein kinases, B-cell lymphoma-2, malondialdehyde, superoxide dismutase
P38MAPK and JNK were all higher in the intermittent hypoxia groups than those in the corresponding continued hypoxia groups. Bcl-2 was mainly increased and reached the highest level at six weeks in the continued hypoxia group. Of note, Bcl-2 rapidly increased to the peak level at four weeks, followed by a decrease to the lowest level at the eighth week in the intermittent hypoxia group. Bax was generally increased at the late stages under continued hypoxia, but increased at all time-points under the intermittent hypoxia conditions. The two types of hypoxia induced an increase in the MDA content, but a decrease in SOD activity. Marked changes in these two parameters coupled with markedly reduced surviving cells in the hippocampus in a time-dependent manner were observed in the intermittent hypoxia group in comparison with the continued hypoxia group. OSAS-induced intermittent hypoxia markedly activated the MAPK signaling pathways, which were triggered by oxidative stress, leading to abnormal expression of downstream Bcl-2 and Bax, and a severe loss of neural cells in the hippocampus.

\section{Introduction}

Obstructive sleep apnea syndrome (OSAS) is a prevalent disorder, affecting $4 \%$ of adults (1). Patients with OSAS manifest with repetitive episodes of transient oxygen de-saturation during sleep, resulting in progressive multisystem damage (2). It has been recently reported that OSAS is an independent risk factor for a number of cerebral vascular disorders and is associated with Alzheimer's disease. Surgical treatment may only partially improve cognitive function in patients with OSAS. Thus, OSAS-induced damage to the brain may be irreversible $(3,4)$. Although the pathophysiological basis of cerebral complications in OSAS is likely to be multifactorial, including sympathetic excitation, cerebral vascular contraction, inflammation, oxidative stress and a disorder of the metabolism (5-8), the precise underlying mechanisms remain to be elucidated and require further investigation.

The mitogen-activated protein kinases (MAPKs) comprise a family of ubiquitous proline-directed protein-serine/threonine kinases, which are essential in the sequential transduction of biological signals from the cell membrane to the nucleus (9). In mammalian cells, there are three well-defined sub-groups 
of MAPKs: Extracellular signal-regulated kinases (ERKs, including ERK1 and ERK2 isoforms), the c-Jun N-terminal kinases (JNKs, including JNK1, JNK2 and JNK3 isoforms), and the P38MAPKs, including P38- $\alpha,-\beta,-\gamma$ and $-\delta$ isoforms. Studies have demonstrated that in mammalian cells, MAPKs can be activated by a variety of stimuli, and in turn, the activated MAPKs may typically phosphorylate a number of downstream substrates, including c-Raf-1, MAPK kinase, ERK-1, and c-Fos, which regulate a number of genes involved in neuronal apoptosis, including B-cell lymphoma 2 (Bcl-2) and caspase-3 (10-12). Studies have demonstrated that sustained cellular hypoxia is associated with the activation of a MAPK pathway mediated by the transcription factor hypoxia-inducible factor-1, vascular endothelial growth factor and inducible nitric oxide synthase (13-15). These factors mediate an adaptive response to hypoxia, and are directed toward increasing tissue perfusion and oxygenation to overcome the initial hypoxic insult. It is known that intermittent episodes of hypoxia, particularly the associated episodes of intermittent re-oxygenation, are an important factor for OSAS-associated cerebral injury. Previous studies by our group have revealed that intermittent episodes of hypoxia changed the degree of JNK activation in the cortex and hippocampus in a rat model of intermittent hypoxia of differing degrees (16). Additional study is required to elucidate the response of the hippocampus, a major component of the brain for memory, to hypoxia by examining the expression of key MAPKs, including ERK1/2, P38MAPK and JNK.

The present study assessed the effects of intermittent hypoxia on MAPKs and the expression of apoptotic genes in the hippocampus of a rat model, which may represent a critical mechanism for OSAS-associated brain damage in humans.

\section{Materials and methods}

Animal model of hypoxia. The protocol of the present study was approved by the ethics committee of North China University of Science and Technology (Tangshan, China). A total of 60 male Sprague-Dawley rats (weight, $170 \pm 10$ g; age, 8 weeks; Beijing Experimental Animal Center, Chinese Academy of Science, Beijing, China) were selected as a model in the present study. The rats were housed in polycarbonate cages with compressed fiber bedding at $21-25^{\circ} \mathrm{C}$ and $40-60 \%$ relative humidity. Food and water were available ad libitum in the cage. The animals were randomly divided into three groups, consisting of control, continued hypoxia and intermittent hypoxia groups, and rats in these three groups were further assigned to 2 nd, 4th, 6th and 8th week sub-groups, each including five rats. The corresponding control sub-groups contained the same quantity of rats.

The animals in the intermittent hypoxia group were kept in a hypoxia chamber with cycled changes of the hypoxic conditions ( $2 \mathrm{~min}$ ) for $8 \mathrm{~h}$ daily between 8:00 am and 4:00 pm. The chamber was filled with nitrogen and compressed air (Gas Tech Hexagonal Co., Ltd., Tianjin, China), and in each cycle, for the first $30 \mathrm{sec}$, the oxygen concentration inside was lowered to $10 \%$ and maintained for $50 \mathrm{sec}$, followed by an increase in the oxygen concentration to $21 \%$ for $40 \mathrm{sec}$. Animals in the continued hypoxia group were kept in the hypoxia chamber, which was filled with nitrogen and compressed air and a continuously maintained oxygen concentration of $10 \%$, for $8 \mathrm{~h}$ between 8:00 am and 4:00 pm. The animals in the control group were kept in the hypoxia by filed with air (21\% oxygen) chamber for $8 \mathrm{~h}$ between 8:00 am and 4:00 pm. The change of the oxygen concentration in the chamber was measured using an oxygen monitor and the oxygen concentration was maintained within the range of required concentrations $\pm 0.5 \%$. Blood $(0.1 \mathrm{ml})$ was extracted from the arteria carotis using a micro-injector, a total of 12 times in one cycle (with measurements performed every $10 \mathrm{sec}$ ). Blood gas values were measured using a blood gas analyzer (AVL OMNI automatic blood analyzer; Roche Diagnostics, Basel, Switzerland).

Tissue preparation. A total of five rats in the control or treatment groups were decapitated under anesthesia (10\% chloral hydrate; $40 \mathrm{mg} / \mathrm{kg}$ i.p). Sections of brain hippocampal tissues were separated and fixed with $4 \%$ paraformaldehyde solution for histological detection and immunohistochemical analysis. Another section of hippocampal tissue was rapidly frozen in liquid nitrogen. The frozen tissue samples were homogenized in 1:10 (w/v) ice-cold homogenization buffer A [10 mM 4-(2-hydroxyethyl)-1-piperazineethanesulfonic acid, $\mathrm{pH}$ 7.9, $0.5 \mathrm{mM} \mathrm{MgCl}_{2}, 10 \mathrm{mM} \mathrm{KCl}, 0.1 \mathrm{mM}$ EDTA, $0.1 \mathrm{mM}$ ethylene glycol tetraacetic acid, $50 \mathrm{mM} \mathrm{NaF}, 5 \mathrm{mM}$ dithiothreitol, $10 \mathrm{mM} \beta$-glycerophosphate, $1 \mathrm{mM}$ sodium orthovanadate, $1 \%$ NP-40 and proteinase inhibitors; $1 \mathrm{mM}$ each of benzamidine, bisnitrophenyl phosphate and phenylmethylsulfonyl fluoride, and $5 \mu \mathrm{g} / \mathrm{ml}$ each of aprotinin, leupeptin and pepstatin A; Xinran Biological Technology Co. Ltd., Shanghai, China], followed by centrifugation at $1,000 \mathrm{xg}$ for $15 \mathrm{~min}$ at $4^{\circ} \mathrm{C}$. The supernatants, as cytosolic components, were collected and the protein concentration was determined.

Histological analysis with hematoxylin and eosin $(H \& E)$ staining. Post-fixed hippocampal brain tissues were embedded in paraffin and cut into $5-\mu \mathrm{m}$ coronal sections using a microtome. Paraffin-embedded brain sections were de-paraffinized with xylene and re-hydrated using an ethanol gradient (100-70\% v/v) (both from Tianjin Sheng Winton Chemical Co., Ltd., Tianjin, China), followed by washing with water. The sections were stained with $0.1 \%$ (w/v) H\&E (Nanjing Aoduofuni Biotechnology Co., Ltd., Nanjing, China), and examined using light microscopy (Olympus BX53; Olympus, Tokyo, Japan). The number of surviving hippocampal CA1 pyramidal cells per $1 \mathrm{~mm}$ length was used to calculate the neuronal density.

Western blot analysis. Protein samples (20 $\mu \mathrm{g}$ each) were separated using 10 or $7.5 \%$ SDS-PAGE (Sigma-Aldrich, St. Louis, MO, USA) and electrotransferred onto nitrocellulose membranes (Bio-Rad Laboratories, Hercules, CA, USA) according to a previously described method (16). Following blocking with $3 \%$ bovine serum albumin for $3 \mathrm{~h}$, the membranes were probed with the following primary antibodies: phosphorylated (p)-ERKl/2 rabbit anti-mouse polyclonal antibody (cat. no. SC7383), p-P38MAPK monoclonal antibody (cat. no. bs-547612), p-JNK (cat. no. elr-0011876) and rabbit polyclonal anti- $\beta$-actin (cat. no. 4970P) (all 1:1,000 dilution; Cell Signaling Technology, Inc., Danvers, MA, USA). Furthermore, Bcl-2 rabbit polyclonal anti-mouse antibody and 

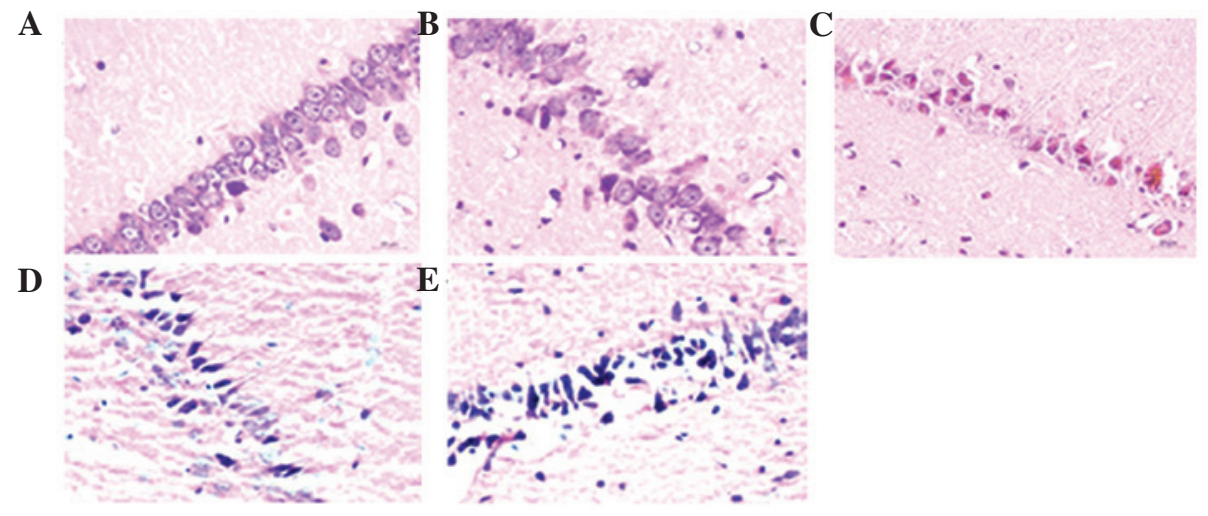

Figure 1. Representative photomicrographs of hematoxylin and eosin-stained sections of hippocampi at the 6th and 8th week after hypoxia (magnification, x400). (A) In the control group, normal cells exhibited round-shaped and pale-stained nuclei. (B and C) Dead cells exhibited a shrunken cytoplasm with pyknotic nuclei in the continued hypoxia group at (B) the 6th week and (C) the 8th week following hypoxia. (D and E) Increased numbers of dead cells in the intermittent hypoxia group at (D) the 6th week and (E) the 8th week following hypoxia.

Bcl-2-associated X protein (Bax) polyclonal rabbit anti-mouse antibody were used (both from Wuhan Boster Biological Engineering Co., Ltd., Wuhan, China). Membrane-bound antibodies were further detected using alkaline phosphatase-conjugated goat anti-mouse or rabbit immunoglobulin (Ig) G (1:10,000 dilution, Sigma-Aldrich). The immunoreactivity was assessed using a NBT/BCIP assay kit (Kexing Biological Technology Co., Ltd., Shanghai, China). The band densities on the membrane were measured using an image analyzer (Lab Works Software version 17.0; UVP Inc., Upland, CA, USA) and normalized to the internal control.

Immunohistochemical analysis. Coronal sections of the tissue samples were blocked in 5\% normal goat serum and then incubated in mouse anti-rat Bax (1:250) or Bcl-2 (1:200) antibody (Santa Cruz Biotechnology, Inc., Dallas, TX, USA) overnight at $4^{\circ} \mathrm{C}$. An equivalent dilution of rat $\operatorname{IgG}$ was used as the primary antibody for the negative control. Subsequently, the sections were incubated in biotinylated rabbit anti-mouse secondary antibody (1:500 dilution) for $90 \mathrm{~min}$ at room temperature followed by incubation with an avidin-biotin complex for $90 \mathrm{~min}$. Finally, the sections were developed with stable 3,3'-diaminobenzidine (DAB color kit; Wuhan Boster Biological Engineering Co., Ltd.) and the nuclei were counter-stained with hematoxylin. Brown-stained positive cells were examined microscopically. Quantitative analysis of positive cells in the hippocampal CA1 region was performed on five slices of each specimen using Motic-6.0 image acquisition and image analysis system (magnification, x200; Motic Med 6.0 digital medical image analysis system; Beijing Aeronautics and Astronautics University, Beijing, China). The ratio of positive cells to the total cell number was calculated.

Malondialdehyde (MDA) and superoxide dismutase (SOD) analysis. The frozen hippocampal tissue samples were homogenized in PBS and centrifuged (12,000 xg for $15 \mathrm{~min})$. The MDA content and the activities of SOD were detected, respectively according to the kit specification. MDA, a lipid peroxide degradation product, was condensed with thiobarbituric acid to form a red product, which was detected at $532 \mathrm{~nm}$ using the MDA test kit from Jiancheng Bioengineering Co., Ltd., Nanjing, China. A standard curve was included in the experiment and the content of MDA was expressed as $\mathrm{nmol} / \mathrm{mg}$ total tissue protein. SOD activity was determined using an enzyme kit (Ransod; Randox Laboratories, Inc., Crumlin, UK). The method employs xanthine and xanthine oxidase to produce superoxide radicals that react with 2-(4-iodophenyl)-3-(4-nitrophenyl)-5-phenyltetrazolium chloride to form a red formazan dye. The SOD activity was measured photometrically by the degree of inhibition of this reaction at $550 \mathrm{~nm}$ at $37^{\circ} \mathrm{C}$ and expressed as $\mathrm{U} / \mathrm{mg}$ total tissue protein. A total of 1 unit of SOD inhibits the rate of increase in absorbance at $550 \mathrm{~nm}$ by $50 \%$ under the conditions of the assay. The SOD activity was determined from the percentage inhibition of the test sample according to an SOD standard curve.

Statistical analysis. All values are expressed as the mean \pm standard deviation. Comparisons between groups were made using one-way analysis of variance and Newman-Keuls test. $\mathrm{P}<0.05$ was considered to indicate a statistically significant difference. SPSS 16.0 (SPSS, Inc., Chicago, IL, USA) was used for analysis.

\section{Results}

Blood gas parameters. The blood $\mathrm{PO}_{2}$ of rats in the control group $\left(21 \% \mathrm{O}_{2}\right)$ was maintained in a range between 98 and $102 \mathrm{mmHg}$; The lowest blood oxygen $\mathrm{PO}_{2}$ of rats in the intermittent hypoxia group $\left(10 \% \mathrm{O}_{2}\right)$ reached $48.8 \mathrm{mmHg}$. In addition, the lowest blood oxygen $\mathrm{PO}_{2}$ of rats in the continued hypoxia group $\left(10 \% \mathrm{O}_{2}\right)$ was maintained in a range between 37.4 and $39.6 \mathrm{mmHg}$.

Intermittent hypoxia causes neuronal cell loss in the hippocampal CAl region. To examine the effects of intermittent hypoxia, as observed in OSAS, on neuronal loss, H\&E staining was performed to examine the survival status of CA1 pyramidal neurons (Fig. 1). The normal cells exhibited round-shaped and pale-stained nuclei. Shrunken cells with pyknotic nuclei following ischemia were counted as dead cells. The number of surviving neurons in the hypoxic groups were significantly lower than that in the control group $(\mathrm{P}<0.05)$ (Table I). In addition, intermittent hypoxia led to a significant neuronal degeneration and the number of surviving neurons in the intermittent hypoxia group was significantly lower than that in the continued hypoxia group $(\mathrm{P}<0.05)$. 
Table I. Rate of surviving nerve cells in the hippocampal CA1 region of rats in various groups (\% of total cells counted).

\begin{tabular}{lcccc}
\hline & \multicolumn{4}{c}{ Rate of survival of nerve cells (\%) } \\
\cline { 2 - 5 } Group & Week 2 & Week 4 & Week 6 & Week 8 \\
\hline Control & $99.4 \pm 06$ & $99.3 \pm 0.7$ & $99.5 \pm 0.5$ & $99.4 \pm 0.6$ \\
Continued & $98.4 \pm 5.6$ & $91.6 \pm 10.8^{\mathrm{a}}$ & $87.2 \pm 19.6^{\mathrm{a}}$ & $84.5 \pm 22.7^{\mathrm{a}}$ \\
Intermittent & $91.50 \pm 16.48^{\mathrm{a}, \mathrm{b}}$ & $82.75 \pm 15.80^{\mathrm{a}, \mathrm{b}}$ & $74.75 \pm 24.70^{\mathrm{a}, \mathrm{b}}$ & $70.70 \pm 26.10^{\mathrm{a}, \mathrm{b}}$ \\
\hline
\end{tabular}

${ }^{\mathrm{a}} \mathrm{P}<0.05$ vs. control, ${ }^{\mathrm{b}} \mathrm{P}<0.05$ vs. continued. Values are expressed as the mean \pm standard deviation from five rats in each subgroup. Control, control group; continued, continued hypoxia group; intermittent, intermittent hypoxia group.

Table II. Phospho-ERK1/2 expression in the hippocampal regions of rats in various groups.

\begin{tabular}{lllll}
\hline & \multicolumn{4}{c}{ Phospho-ERK1/2 expression (band densities) } \\
\cline { 2 - 5 } Group & Week 2 & Week 4 & Week 6 & Week 8 \\
\hline Control & $0.52 \pm 0.15$ & $0.48 \pm 0.12$ & $0.64 \pm 0.18$ & $0.44 \pm 0.18$ \\
Continued & $2.49 \pm 0.96^{\mathrm{a}}$ & $5.84 \pm 1.17^{\mathrm{a}}$ & $3.58 \pm 1.02^{\mathrm{a}}$ & $1.96 \pm 0.82^{\mathrm{a}}$ \\
Intermittent & $4.68 \pm 1.56^{\mathrm{a}, \mathrm{b}}$ & $6.10 \pm 1.12^{\mathrm{a}, \mathrm{b}}$ & $7.86 \pm 1.56^{\mathrm{a}, \mathrm{b}}$ & $9.78 \pm 3.41^{\mathrm{a}, \mathrm{b}}$ \\
\hline
\end{tabular}

${ }^{\mathrm{a}} \mathrm{P}<0.05$ vs. the control group; ${ }^{\mathrm{b}} \mathrm{P}<0.05$ vs. the continued group. Values are expressed as the mean \pm standard deviation from five rats in each subgroup. Control, control group; continued, continued hypoxia group; intermittent, intermittent hypoxia group; ERK, extracellular signal-regulated kinase.

MAPK phosphorylation is increased following intermittent hypoxia. Western blot analysis revealed that levels of phosphorylated ERK1/2, P38MAPK and JNK in the continued hypoxia group were significantly higher than those in the control group $(\mathrm{P}<0.05)$, and levels of phosphorylated ERK1/2 were increased from the 2 nd week and reached a peak at the 4th week, then declined after hypoxia, while the levels of phosphorylated P38MAPK and JNK were gradually increased and peaked at the 8th week after hypoxia. By contrast, the levels of phosphorylated ERK1/2, P38MAPK and JNK in the intermittent hypoxia group were all markedly and constantly increased from the 2 nd week to the 8 th week after hypoxia. In addition, the levels of phosphorylated ERK1/2, P38MAPK and JNK in the intermittent hypoxia group were significantly higher than those in the continued hypoxia group at all time-points $(\mathrm{P}<0.05$; Figs. 2-4; Tables II-IV).

Bax and Bcl-2 are increased following intermittent hypoxia. To verify the downstream effects of MAPK activation following intermittent hypoxia in the rat model of OSAS, immunohistochemical assays were performed to identify the expression of two members of the Bcl-2 family, namely the pro-apoptotic protein Bax and the anti-apoptotic protein Bcl-2. The results revealed an increase in Bcl-2 expression at the 2nd, 4th and 6th week, but a decease at the 8 th week in the continued hypoxia group in comparison to that in the control group. By contrast, Bcl-2 expression was increased at the 2nd and 4th week, but deceased at the 6th and 8th week in the intermittent hypoxia group. In addition, the levels of $\mathrm{Bcl}-2$ in the intermittent hypoxia group were significantly higher than those in the continued hypoxia group at the high end of the range $(33.84 \pm 8.32$ at the 4th week in the intermittent hypoxia group vs. $30.96 \pm 9.66$ at the 6th week in the continued hypoxia group) and at the low end of the range $(9.24 \pm 2.42$ the intermittent group vs. $14.36 \pm 4.46$ in the continued group at the 8th week) levels (Table V and Fig. 5). Bax expression in the continued hypoxia group was significantly higher than that in the control group $(\mathrm{P}<0.05)$ at the 6th and 8th week, whereas its expression in the intermittent hypoxia group was increased at all experimental time-points (Table VI and Fig. 6). The Bcl-2/Bax ratio was markedly lower in the intermittent hypoxia group than that in the continued hypoxia group $(\mathrm{P}<0.05$; Table VII.

Analysis of MDA and SOD activity. To further identify the association between oxidative stress and MAPK activation, changes in MDA, a lipid metabolic product in the oxidative reaction, and SOD, an important anti-oxidant, in the experimental hypoxia groups. The results demonstrated that the MDA content increased in the two hypoxia groups and was significantly elevated compared to that in the control $(\mathrm{P}<0.05)$. The MDA content reached a peak level at the 6th and the 8th week, respectively, in the continued and the intermittent hypoxia groups. Of note, the MDA content in the intermittent hypoxia group was significantly higher than that in the continued hypoxia group at each time-point $(\mathrm{P}<0.05)$ (Table VIII). The SOD activity was decreased and reached its lowest level at the 6th week in the two hypoxia groups and this low level of SOD persisted until the 8th week of the experiments. In addition, the SOD activity in the intermittent hypoxia group was consistently lower than that in the continued hypoxia group (Table IX). 
Table III. Phopho-P38MAPK expression in the hippocampal regions of rats in various groups.

\begin{tabular}{lcccc}
\hline & \multicolumn{3}{c}{ Phospho-P38MAPK expression (band densities) } \\
\cline { 2 - 4 } Group & Week 2 & Week 4 & Week 6 & Week 8 \\
\hline Control & $0.60 \pm 0.17$ & $0.62 \pm 0.18$ & $0.68 \pm 0.22$ & $0.48 \pm 0.12$ \\
Continued & $1.17 \pm 0.24$ & $1.18 \pm 0.20^{\mathrm{a}}$ & $2.49 \pm 0.96^{\mathrm{a}}$ & $3.12 \pm 0.23^{\mathrm{a}}$ \\
Intermittent & $2.96 \pm 0.32^{\mathrm{a}, \mathrm{b}}$ & $3.40 \pm 0.42^{\mathrm{a}, \mathrm{b}}$ & $4.98 \pm 0.56^{\mathrm{a}, \mathrm{b}}$ & $6.84 \pm 1.01^{\mathrm{a}, \mathrm{b}}$ \\
\hline
\end{tabular}

${ }^{\mathrm{a}} \mathrm{P}<0.05$ vs. the control group; ${ }^{\mathrm{b}} \mathrm{P}<0.05$ vs. the continued group. Values are expressed as the mean \pm standard deviation from five rats in each subgroup. Control, control group; continued, continued hypoxia group; intermittent, intermittent hypoxia group; MAPK, mitogen-activated protein kinase.

Table IV. Phospho-JNK expression in the hippocampal regions of rats in various groups.

\begin{tabular}{lllll}
\hline & \multicolumn{4}{c}{ Phospho-JNK expression (band densities) } \\
\cline { 2 - 5 } Group & Week 2 & Week 4 & Week 6 & Week 8 \\
\hline Control & $0.68 \pm 0.22$ & $0.64 \pm 0.20$ & $0.66 \pm 0.20$ & $0.68 \pm 0.24$ \\
Continued & $1.12 \pm 0.28^{\mathrm{a}}$ & $1.18 \pm 0.26^{\mathrm{a}}$ & $3.40 \pm 0.42^{\mathrm{a}}$ & $4.98 \pm 0.56^{\mathrm{a}}$ \\
Intermittent & $1.82 \pm 0.25^{\mathrm{a}, \mathrm{b}}$ & $3.07 \pm 0.19^{\mathrm{a}, \mathrm{b}}$ & $4.75 \pm 0.32^{\mathrm{a}, \mathrm{b}}$ & $8.72 \pm 1.40^{\mathrm{a}, \mathrm{b}}$
\end{tabular}

${ }^{\mathrm{a}} \mathrm{P}<0.05$ vs. the control group; ${ }^{\mathrm{b}} \mathrm{P}<0.05$ vs. the continued group. Values are expressed as the mean \pm standard deviation from five rats in each subgroup. Control, control group; continued, continued hypoxia group; intermittent, intermittent hypoxia group; JNK, c-Jun N-terminal kinase.

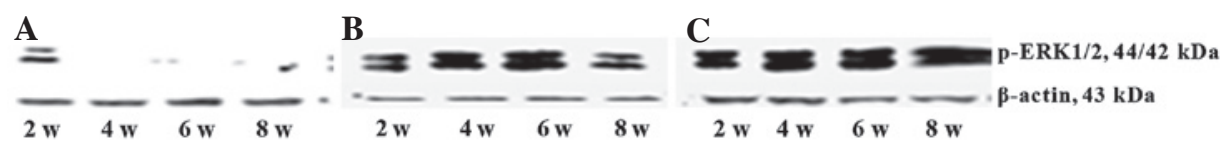

Figure 2. Western blots of phospho-ERK1/2 expression in hippocampal regions. (A) Control group; (B) continued hypoxia group; (C) intermittent hypoxia group. p-ERK, phosphorylated extracellular signal-regulated kinase; w, weeks.

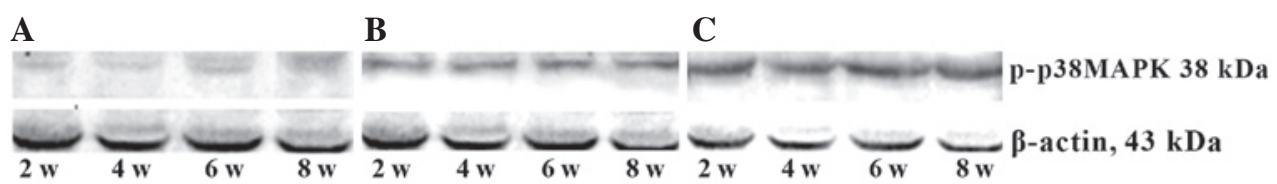

Figure 3. Western blots of phospho-P38MAPK expression in hippocampal regions. (A) Control group; (B) continued hypoxia group; (C) intermittent hypoxia group. MAPK, mitogen-activated protein kinase.

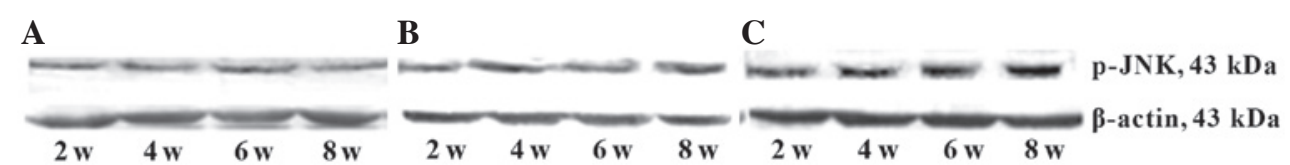

Figure 4. Western blots of phospho-JNK expression in hippocampal regions. (A) control group; (B) continued hypoxia group; (C) intermittent hypoxia group. JNK, c-Jun N-terminal kinase.

\section{Discussion}

OSAS is widely recognized as an independent risk factor for cerebrovascular diseases, particularly cerebral stroke. It increases the incidence of cerebral stroke by two times even after adjustment for potential confounding factors (15). In addition, the majority of patients with OSAS exhibit symptoms of nervous system damage, manifested as a dysfunction in learning, memory and decision-making ability (17). Mitchell et al (18) reported that cognitive function in patients with OSAS was only partially improved, even following surgical treatment. Furthermore, it is associated with changes 
Table V. Rate of Bcl-2-positive cells in the hippocampal CA1 region of rats in response to hypoxia.

\begin{tabular}{lcccc}
\hline & \multicolumn{4}{c}{ Rate of Bcl-2-positive cells (\%) } \\
\cline { 2 - 5 } Group & Week 2 & Week 4 & Week 6 & \\
\hline Control & $5.56 \pm 1.10$ & $5.58 \pm 1.12$ & $5.52 \pm 1.11$ & Week 8 \\
Continued & $16.54 \pm 3.96^{\mathrm{a}}$ & $24.64 \pm 5.74^{\mathrm{a}}$ & $30.96 \pm 8.32^{\mathrm{a}}$ & $5.28 \pm 1.10$ \\
Intermittent & $24.86 \pm 6.38^{\mathrm{a}, \mathrm{b}}$ & $33.84 \pm 9.66^{\mathrm{a}, \mathrm{b}}$ & $20.78 \pm 5.36^{\mathrm{a}, \mathrm{b}}$ & $14.36 \pm 4.60^{\mathrm{a}}$ \\
& & & $9.24 \pm 2.42^{\mathrm{a}, \mathrm{b}}$
\end{tabular}

${ }^{\mathrm{a}} \mathrm{P}<0.05$ vs. the control group; ${ }^{\mathrm{b}} \mathrm{P}<0.05$ vs. the continued group. Values are expressed as the mean \pm standard deviation from five rats in each subgroup. Control, control group; continued, continued hypoxia group; intermittent, intermittent hypoxia group; Bcl-2, B-cell lymphoma-2.

Table VI. Rate of Bax-positive cells in the hippocampal CA1 region of rats in response to hypoxia.

\begin{tabular}{lcccc}
\hline & \multicolumn{4}{c}{ Rate of Bax-positive cells } \\
\cline { 2 - 5 } Group & Week 2 & Week 4 & Week 6 & Week 8 \\
\hline Control & $2.78 \pm 0.82$ & $2.66 \pm 0.76$ & $2.64 \pm 0.78$ & $2.70 \pm 0.82$ \\
Continued & $4.14 \pm 1.56$ & $4.08 \pm 1.64$ & $9.72 \pm 2.80^{\mathrm{a}}$ & $22.68 \pm 6.94^{\mathrm{a}}$ \\
Intermittent & $11.44 \pm 3.24^{\mathrm{a}, \mathrm{b}}$ & $18.80 \pm 4.60^{\mathrm{a}, \mathrm{b}}$ & $26.64 \pm 8.26^{\mathrm{a}, \mathrm{b}}$ & $32.72 \pm 9.24^{\mathrm{a}, \mathrm{b}}$ \\
\hline
\end{tabular}

${ }^{\mathrm{a}} \mathrm{P}<0.05$ vs. the control group; ${ }^{\mathrm{b}} \mathrm{P}<0.05$ vs. the continued group. Values are expressed as the mean \pm standard deviation from five rats in each subgroup. Bax, B-cell lymphoma-2-associated X protein. Control, control group; continued, continued hypoxia group; intermittent, intermittent hypoxia group.

Table VII. Ratio of Bcl-2/Bax-positive cells in the hippocampal CA1 region of rats in response to hypoxia.

\begin{tabular}{lcccc}
\hline & \multicolumn{4}{c}{ Rate of positive cells (fold) } \\
\cline { 2 - 5 } Group & Week 2 & Week 4 & Week 6 & Week 8 \\
\hline Control & 2.0 & 2.1 & 2.1 & 2.0 \\
Continued & 4.0 & 6.0 & 3.2 & 0.6 \\
Intermittent & 2.2 & 1.8 & 0.8 & 0.8 \\
\hline
\end{tabular}

Control, control group; continued, continued hypoxia group; intermittent, intermittent hypoxia group; Bcl-2, B-cell lymphoma-2; Bax, Bcl-2-associated X protein.

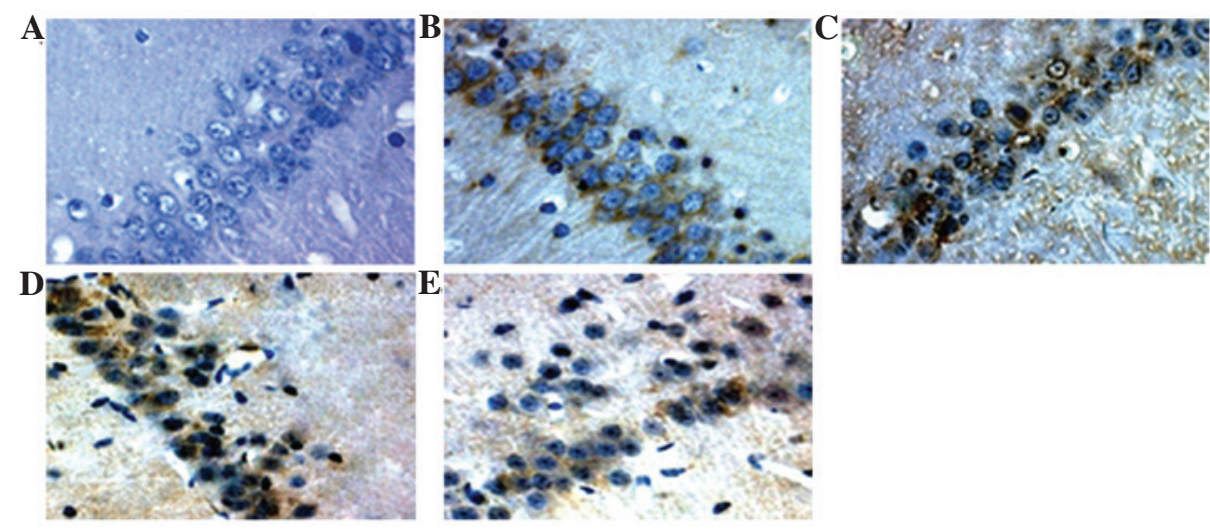

Figure 5. Bcl-2-positive cells revealed by immunohistochemistry in the hippocampus following hypoxia (magnification, x400). (A) Few Bcl-2-positive cells in the control group; (B) Numerous Bcl-2-positive cells with brown-staining at the 6th week, and (C) decreased number of positive cells at the 8th week in the continued hypoxia group; (D) Numerous Bcl-2 positive cells at the 2nd week and (E) decreased number of positive cells at the 6th week in the intermittent hypoxia group. Bcl-2, B cell lymphoma-2. 
Table VIII. Quantitative analysis of the malondialdehyde content in the hippocampal CA1 region of rats in response to hypoxia.

\begin{tabular}{lcccc}
\hline & \multicolumn{4}{c}{ Malondialdehyde content (nM/mg total tissue protein) } \\
\cline { 2 - 5 } Group & Week 2 & Week 4 & Week 6 & Week 8 \\
\hline Control & $7.60 \pm 1.47$ & $7.58 \pm 1.48$ & $7.58 \pm 1.46$ & $7.62 \pm 1.50$ \\
Continued & $9.70 \pm 1.83^{\mathrm{a}}$ & $12.70 \pm 4.86^{\mathrm{a}}$ & $27.94 \pm 7.54^{\mathrm{a}}$ & $22.42 \pm 8.94^{\mathrm{a}}$ \\
Intermittent & $14.38 \pm 3.36^{\mathrm{a}, \mathrm{b}}$ & $18.82 \pm 5.58^{\mathrm{a}, \mathrm{b}}$ & $34.96 \pm 9.32^{\mathrm{a}, \mathrm{b}}$ & $39.92 \pm 11.28^{\mathrm{a}, \mathrm{b}}$ \\
\hline
\end{tabular}

${ }^{\mathrm{a}} \mathrm{P}<0.05$, vs. the control group; ${ }^{\mathrm{b}} \mathrm{P}<0.05$, vs. the continued hypoxia group. Values are expressed as the mean \pm standard deviation from five rats in each subgroup. Control, control group; continued, continued hypoxia group; intermittent, intermittent hypoxia group.

Table IX. Quantitative analysis of superoxide dismutase activity in the hippocampal CA1 region of rats in response to hypoxia.

\begin{tabular}{lcccc}
\hline & \multicolumn{4}{c}{ Superoxide dismutase activity (U/mg total tissue protein) } \\
\cline { 2 - 5 } Groups & Week 2 & Week 4 & Week 6 & Week 8 \\
\hline Control & $87.68 \pm 2.32$ & $87.70 \pm 2.38$ & $87.66 \pm 2.30$ & $87.70 \pm 2.36$ \\
Continued & $76.68 \pm 2.68^{\mathrm{a}}$ & $68.50 \pm 2.62^{\mathrm{a}}$ & $60.94 \pm 2.54^{\mathrm{a}}$ & $67.42 \pm 2.94^{\mathrm{a}}$ \\
Intermittent & $68.62 \pm 2.66^{\mathrm{a}, \mathrm{b}}$ & $60.82 \pm 2.58^{\mathrm{a}, \mathrm{b}}$ & $54.96 \pm 2.32^{\mathrm{a}, \mathrm{b}}$ & $55.92 \pm 3.08^{\mathrm{a}, \mathrm{b}}$ \\
\hline
\end{tabular}

${ }^{\mathrm{a}} \mathrm{P}<0.05$, vs. the control group; ${ }^{\mathrm{b}}<0.05$, vs. the continued hypoxia group. Values are expressed as the mean \pm standard deviation from five rats in each subgroup. Control, control group; continued, continued hypoxia group; intermittent, intermittent hypoxia group.

A

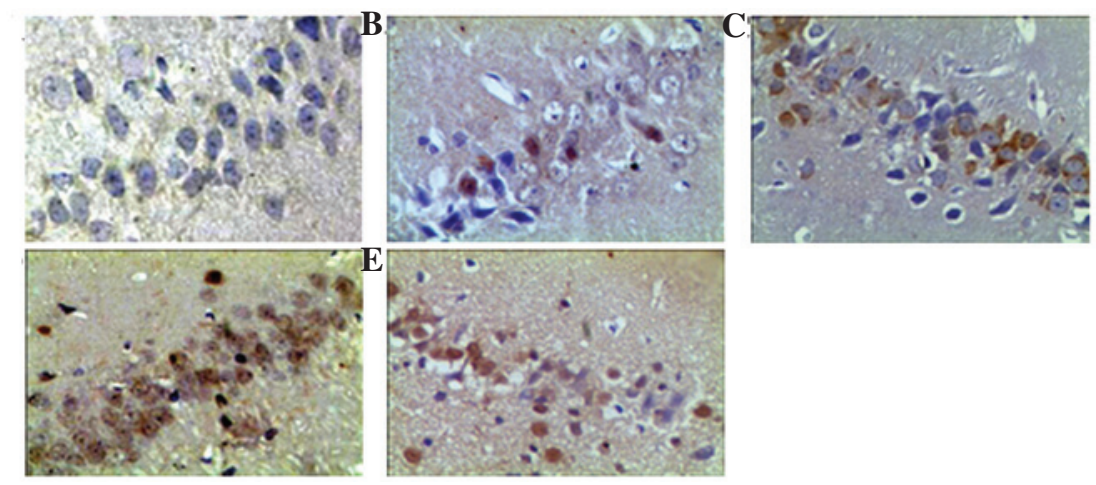

Figure 6. Bax-positive cells were detected using immunohistochemistry in the hippocampus after hypoxia (magnification, x400). (A) Few Bax-positive cells in the control group. (B) Numerous Bax-positive cells with brown staining at the 6th week in continued hypoxia. (C) The number of Bax-positive cells was maximal at the 8th week in continued hypoxia; (D) Bax-positive cells at the 2nd week and (E) at the 8th week in the intermittent hypoxia group. Bax, Bcl-2-associated X protein.

in brain structure, including a reduction in the gray matter in the hippocampus, frontal cortex, anterior cingulate cortex and other sections as well as volume atrophy (19-20). A previous study by our group demonstrated that various degrees of intermittent hypoxia induced injury to the neural cell ultrastructure as well as nerve cell loss, which were irreversible (21). In the present study, it was illustrated that intermittent hypoxia elicited a severe level of neuronal degeneration and neuronal death in comparison to continued hypoxia in a rat model, suggesting that intermittent hypoxia in OSAS may induce marked damage to nerve cells.

The MAPK pathway is activated in the brains of animal models of cerebral ischemia; furthermore, it has been demonstrated that the MAPK signaling pathway is important in cerebral ischemia/reperfusion, the closed head injury model and perinatal hypoxia-ischemia (22-24). Further studies have also assessed the timing and location of the MAPK activation in various brain tissues under different stress conditions. Guo et al (25) proposed that ERK1/2 activity, instead of JNK1/2 activity, was increased $30 \mathrm{~min}$ after cerebral ischemia in a model of permanent forebrain ischemia in rats induced using the four artery ligation method. In a cerebral ischemia-re-perfusion model, the ERK1/2 activity began to increase at $15 \mathrm{~min}$ and peaked at $6 \mathrm{~h}$, while JNK1/2 activity increased after $1 \mathrm{~h}$ and gradually increased to peak at $21 \mathrm{~h}$; both activated $\mathrm{ERKl} / 2$ and $\mathrm{JNKl} / 2$ were detected at $24 \mathrm{~h}$ after injury. It is noteworthy that activated ERK1/2 instead of $\mathrm{JNKl} / 2$ was also induced by another re-perfusion (26). In a gerbil model of brain ischemia-re-perfusion induced by bilateral 
common carotid artery blocking, indications of MAPK activation, including ERKl/2 phosphorylation, mainly existed in the CA3/dentate gyrus sub-region at a short time after ischemia and was lowly expressed in the CA1 sub-region. With the extension of ischemia, JNKl/2 and P38MAPK phosphorylation levels were increased in the CA1 and CA3 sub-regions (27). In the present study, western blot analysis indicated that in the continued hypoxia model, phospho-ERK1/2 was markedly increased at various time-points and reached a peak level at four weeks, after which it declined. With increasing time following hypoxia, active P38MAPK and JNK1/2 were detected. In the intermittent hypoxia group, phospho-ERKl/2, P38MAPK and JNK1/2 increased markedly from two weeks after hypoxia, and ERK1/2 activity maintained a stable increase to the top level from the 2 nd to the 8 th week in the experimental period. Activated P38MAPK and JNK1/2 were gradually increased, reaching their highest levels at the 8 th week also. The results of the present study suggested that the MAPK signaling pathways were selectively activated under various hypoxic conditions. It is possible that intermittent hypoxia induced by OSAS activated MAPK signaling pathways in a continually excessive manner. It is known that P38MAPK and JNK are similar in nature, and the activation of either has a negative regulatory role, leading to cell injury and death $(11,12,28)$. By contrast, ERK1/2 has a dual effect, which may promote cell survival and proliferation with appropriate activation in the short term, but may also cause cell death with excessive activation in the long term $(29,30)$. Alessandrini et al (31) demonstrated that ERK1/2 phosphorylation and cytochrome $\mathrm{C}$ were increased following cerebral injury, and co-localized within the same nerve cell. The activation of ERK1/2 may upregulate the protective anti-oxidant system and promote neuronal survival (32). The Ras/ERK1/2 cascade has been hypothesized to be a tolerance core of neurons in cerebral ischemic stress (33). In fact, MAPK activation in mammalian cells has coordinating effects and the same simulation is able to activate various MAPK pathways. For example, stress reactions are able to activate the ERK1/2, P38MAPK and JNK1/2 pathways (34), while epidermal growth factor may stimulate ERK1/2 and JNK1/2 signals (35). In addition, activated MAPKs may phosphorylate or activate the same transcription factor, such as ERK-1, and thus integrate extracellular stimuli, ultimately leading to biological reactions to induce cell survival or death (36).

In the present study, certain correlations between activated $\mathrm{ERKl} / 2$ and the expression of $\mathrm{Bcl}-2$ family members were identified. The levels of Bcl-2 and ERK1/2 began to increase at the 2 nd week and reached a peak at the 4 th week or the 6 th week, and then decreased in the continued hypoxia group. Bax expression gradually increased and reached a peak at the 8th week in association with a decrease in phospho-ERK1/2 and increases in activated P38MAPK and JNK1/2 in the continued hypoxia group. In the intermittent hypoxia group, activated ERKl/2 maintained a steady increase reaching the top level at the 8th week; however, Bcl-2 expression reached a peak at 4 weeks and then gradually decreased. It is well established that Bcl-2 and Bax exhibit the opposite biological functions. Bcl-2 is able to enhance cell survival following ischemia and hypoxia by maintaining mitochondrial membrane integrity, whereas Bax promotes ischemia or hypoxia-induced cell death via the release of cytochrome $\mathrm{C}$. Thus, the ratio of $\mathrm{Bcl}-2$ to $\mathrm{Bax}$ affects the survival of cells $(37,38)$. Based on changes in the ratio of Bcl-2 to Bax and MAPK signaling pathway activation under various hypoxic conditions, the present study hypothesized that in the continued hypoxia group, ERK1/2 activation may have had a protective effect and enhanced Bcl-2 expression. This may have increased the compensatory function of nerve cells resistant to low oxygen. However, the intermittent hypoxia of OSAS may resemble re-perfusion injury, resulting in a marked stress reaction and continued, excessive activation of the MAPK signaling pathways. The possible role of ERK1/2 activation at the early stages may have increased the tolerance to hypoxia for a short period. However, with prolonged intermittent hypoxia, the MAPK signaling pathway was excessively activated, leading to abnormal expression of $\mathrm{Bcl}-2$ and $\mathrm{Bax}$ and the death of nerve cells. This may be an important molecular mechanism for OSAS-associated injury to the brain.

In the animal model, hypoxia enhanced the production of MDA and reduced the activity of SOD in a time-dependent manner, particularly in the intermittent hypoxia group. Hypoxia has been reported to result in a marked elevation in reactive oxygen species (ROS) in non-brain tissues (39). The present study illustrated differences in the type and extent hypoxia on MAPK activation, including increases of MDA or decreases of SOD, suggesting an association between changes in the oxidative stress reaction and MAPK activation in the pathological process of nerve injury induced by hypoxia. Direct exposure of cells to exogenous $\mathrm{H}_{2} \mathrm{O}_{2}$, to mimic oxidative stress, leads to the activation of MAPKs (40). The prevention of ROS accumulation by anti-oxidants blocks MAPK activation in cells exposed to specific stimuli $(41,42)$. A previous study by our group reported that oxidative stress initiated the JNK pathway, which mediated nerve cell injury in a model of severe intermittent hypoxia (41). ROS may trigger the ERK1/2 pathway through activation of growth factor receptors (43) or modification of apoptosis signal-regulating kinase 1 , a member of the MAP3K superfamily, which targets JNK and P38MAPK. In addition, ROS oxidize the cysteine residues in MAPK phosphatase, leading to activation of the JNK and P38 pathways. Under the conditions of intermittent hypoxia found in OSAS, oxidative reactions due to marked repetitive re-oxygenation enhance the early damage of nerve cells.

In conclusion, the present animal study indicated that MAPK signaling pathways were selectively activated in the hippocampus under intermittent and continued hypoxic conditions. In addition, excessive activation of MAPK signaling pathways by intermittent hypoxia elicited abnormal expression of Bcl-2 and Bax as well as a severe loss of hippocampal nerve cells. This phenomenon was also closely associated with oxidative stress, inducing an elevated production of MDA and the downregulation of SOD. These findings suggested a critical role of MAPK activation in OSAS-induced brain pathogenesis, and provided therapeutic strategies for the prevention and treatment of this common disease.

\section{Acknowledgements}

The present study was supported by grants from the Natural Science Foundation, Department of Education, Hebei Province (grant no. ZH201120) and the Hebei Province Science and Technology Project (grant no. 09276103D-11), China. 


\section{References}

1. Young T, Palta M, Dempsey J, Skatrud J, Weber S and Badr S: The occurrence of sleep-disordered breathing among middle-aged adults. N Engl J Med 328: 1230-1235, 1993.

2. Peppard PE, Young T, Palta M and Skatrud J: Prospective study of the association between sleep-disordered breathing and hypertension. N Engl J Med 342: 1378-1384, 2000.

3. Durgan DJ and Bryan RM Jr: Cerebrovascular consequences of obstructive sleep apnea. J Am Heart Assoc 1: e000091, 2012.

4. Baessler A, Nadeem R, Harvey M, Madbouly E, Younus A, Sajid H, Naseem J, Asif A and Bawaadam H: Treatment for sleep apnea by continuous positive airway pressure improves levels of inflammatory markers-a meta-analysis. J Inflamm (Lond) 10: 13, 2013.

5. Opstad KS, Provencher SW, Bell BA, et al: Detection of elevated glutathione in meningiomas by quantitative in vivo 1H MRS. Magn Reson Med 49: 632-637, 2003.

6. Hagen T, Taylor CT, Lam F and Moncada S: Redistribution of intracellular oxygen in hypoxia by nitric oxide: Effect on HIF1alpha. Science 302: 1975-1978, 2003.

7. Ohga E, Nagase T, Tomita T, Teramoto S, Matsuse T, Katayama $\mathrm{H}$ and Ouchi Y: Increased levels of circulating ICAM-1, VCAM-1 and L-selectin in obstructive sleep apnea syndrome. J Appl Physiol (1985) 87: 10-14, 1999.

8. Yuan G, Nanduri J, Bhasker CR, Semenza GL and Prabhakar NR: Ca2+/calmodulin kinase-dependent activation of hypoxia-inducible factor 1 transcriptional activity in cells subjected to intermittent hypoxia. J Biol Chem 280: 4321-4328, 2005

9. Broom OJ, Widjaya B, Troelsen J, Olsen J and Nielsen OH: Mitogen activated protein kinases: A role in inflammatory bowel disease? Clin Exp Immunol 158: 272-280, 2009.

10. Suganuma T and Workman JL: MAP kinases and histone modification. J Mol Cell Biol 4: 348-350, 2012.

11. Kyriakis JM and Avruch J: Mammalian MAPK signal transduction pathways activated by stress and inflammation: A 10-year update. Physiol Rev 92: 689-737, 2012.

12. Cargnello $M$ and Roux PP: Activation and function of the MAPKs and their substrates, the MAPK-activated protein kinases. Microbiol Mol Biol Rev 75: 50-83, 2011.

13. Lawrence MC, Jivan A, Shao C, Duan L, Goad D, Zaganjor E, Osborne J, McGlynn K, Stippec S, Earnest S, et al: The roles of MAPKs in disease. Cell Res 18: 436-442, 2008.

14. Kiec-Wilk B, Grzybowska-Galuszka J, Polus A, Pryjma J, Knapp A and Kristiansen K: The MAPK-dependent regulation of the Jagged/Notch gene expression by VEGF, bFGF or PPAR gamma mediated angiogenesis in HUVEC. J Physiol Pharmacol 61: 217-225, 2010

15. Yoon SY, Lee YJ, Seo JH, Sung HJ, Park KH, Choi IK, Kim SJ, Oh SC, Choi CW, Kim BS, et al: uPAR expression under hypoxic conditions depends on iNOS modulated ERK phosphorylation in the MDA-MB-231 breast carcinoma cell line. Cell Res 16: 75-81, 2006.

16. Zhao YN, Wang HY, Guo X, et al: Phospho-JNK expression and significance of hippocampus of rats to varying degrees intermittent hypoxia. J Jilin Univ 38: 1135-1140, 2012.

17. Sateia MJ: Neuropsychological impairment and quality of life in obstructive sleep apnea. Clin Chest Med 24: 249-259, 2003

18. Mitchell RB, Kelly J, Call E and Yao N: Long-term changes in quality of life after surgery for pediatric obstructive sleep apnea. Arch Otolaryngol Head Neck Surg 130: 409-412, 2004.

19. Alchanatis M, Zias N, Deligiorgis N, Amfilochiou A, Dionellis G and Orphanidou D: Sleep apnea-related cognitive deficits and intelligence: An implication of cognitive reserve theory. J Sleep Res 14: 69-75, 2005.

20. Rao BS, Raju TR and Meti BL: Increased numerical density of synapses in CA3 region of hippocampus and molecular layer of motor cortex after self-stimulation rewarding experience. Neuroscience 91: 799-803, 1999.

21. Li L, Wang HY and Zhao YN: The effects of intermittent serious hypoxia on the cognitive function and hippocampus ultra microstructure in Rats. Xi'an Jiaotong University (Medical Sciences) 32: 687-689, 2011.

22. Hu B, Liu C, Bramlett H, Sick TJ, Alonso OF, Chen S and Dietrich WD: Changes in TrkB-ERK1/2-CREB/ELK-1 pathways in hippocampal mossy fiber organization after traumatic brain injury. J Cereb Blood Flow Metab 24: 934-943, 2004
23. Lu K, Cho CL, Liang CL, Chen SD, Liliang PC, Wang SY and Chen HJ: Inhibition of the MEK/ERK pathway reduces microglial activation and interleukin-1-beta expression in spinal cord ischemia/reperfusion injury in rats. J Thorac Cardiovasc Surg 133: 934-941, 2007.

24. Lee SR and Lo EH: Interactions between p38 mitogen-activated protein kinase and caspase- 3 in cerebral endothelial cell death after hypoxia-reoxygenation. Stroke 34: 2704-2709, 2003.

25. Guo J, Zhu H and De W: Mitogen-activated protein kinases ERKs and JNKs differences in brain ischemia activation and regulation mechanism. Chin J Neurosci 20: 207-221, 2004.

26. Guo J, Meng F, Zhang G and Zhang Q: Free radical are involved in continuous activation of non receptor tyrosine protein kinase c-Src after ischemia/reperfusion in rat hippocampus. Neurosci Lett 345: 101-104, 2003.

27. Chandler LJ, Sutton G, Dorairaj NR and Norwood D: N-Methyl $\mathrm{D}$-aspartate receptor-mediated bidirectional control of extracellular signal regulated kinase activity in cortical neuronal cultures. J Biol Chem 276: 2627-2636, 2001.

28. Kaminska B, Gozdz A, Zawadzka M, Ellert-Miklaszewska A and Lipko M: MAPK signal transduction underlying brain inflammation and gliosis as therapeutic target. Anat Rec (Hoboken) 292: 1902-1913, 2009.

29. Clausen F, Lundqvist H, Ekmark S, Lewén A, Ebendal T and Hillered L: Oxygen free radical-dependent activation of extracellular signal-regulated kinase mediates apoptosis-like cell death after traumatic brain injury. J Neurotrauma 21: 1168-1182, 2004.

30. Berkeley JL, Decker MJ and Levey AI: The role of muscarinic acetylcholine receptor-mediated activation of extracellular signal-regulated kinase $1 / 2$ in pilocarpine-induced seizures. J Neurochem 82: 192-201, 2002.

31. Alessandrini A, Namura S, Moskowitz MA and Bonventre JV: MEK1 protein kinase inhibition protects against damage resulting from focal cerebral ischemia. Proc Natl Acad Sci USA 96: 12866-12869, 1999.

32. Zhang P, Wang YZ, Kagan E and Bonner JC: Peroxynitrite targets the epidermal growth factor receptor, Raf-1 and MEK independently to activate MAPK. J Biol Chem 275: 22479-22486, 2000.

33. Jin K, Mao XO, Zhu Y and Greenberg DA: MEK and ERK protect hypoxic cortical neurons via phosphorylation of Bad. J Neurochem 80: 119-125, 2002.

34. Dasari A and Messersmith WA: New strategies in colorectal cancer: Biomarkers of response to epidermal growth factor receptor monoclonal antibodies and potential therapeutic targets in phosphoinositide 3-kinase and mitogen-activated protein kinase pathways. Clin Cancer Res 16: 3811-3818, 2010.

35. Ma FY, Liu J and Nikolic-Paterson DJ: The role of stress-activated protein kinase signaling in renal pathophysiology. Braz J Med Biol Res 42: 29-37, 2009.

36. Ge X, Shi Z, Yu N, Jiao Y, Jin L and Zhang J: The Role of EGFR/ERK/ELK-1 MAP kinase pathway in the underlying damage to diabetic rat skin. Indian J Dermatol 58: 101-106, 2013.

37. Pirzadeh A, Mammen A, Kubin J, Reade E, Liu H, Mendoza A, Greeley WJ, Wilson DF and Pastuszko A: Early regional response of apoptotic activity in newborn piglet brain following hypoxia and ischemia. Neurochem Res 36: 83-92, 2011.

38. Hagberg H, Mallard C, Rousset CI and Xiaoyang Wang: Apoptotic mechanisms in the immature brain: Involvement of mitochondria. J Child Neurol 24: 1141-1146, 2009.

39. Clanton TL: Hypoxia-induced reactive oxygen species formation in skeletal muscle. J Appl Physiol 102: 2379-2388, 2007.

40. Posen Y, Kalchenko V, Seger R, Brandis A, Scherz A and Salomon Y: Manipulation of redox signaling in mammalian cells enabled by controlled photogeneration of reactive oxygen species. J Cell Sci 118: 1957-1969, 2005.

41. Kyaw M, Yoshizumi M, Tsuchiya K, Kirima K and Tamaki T: Antioxidants inhibit JNK and p38 MAPK activation but not ERK $1 / 2$ activation by angiotensin II in rat aortic smooth muscle cells. Hypertens Res 24: 251-261, 2001.

42. Yeo JE and Kang SK: Selenium effectively inhibits ROS-mediated apoptotic neural precursor cell death in vitro and in vivo in traumatic brain injury. Biochim Biophys Acta 1772: 1199-1210, 2007.

43. Akool el-S, Gauer S, Osman B, Doller A, Schulz S, Geiger H, Pfeilschifter J and Eberhardt W: Cyclosporin A and tacrolimus induce renal Erk1/2 pathway via ROS-induced and metalloproteinase-dependent EGF-receptor signaling. Biochem Pharmacol 83: 286-295, 2012. 